\title{
Papillon Lefevre Syndrome: A Case Report with Review
}

\section{Bhawandeep Kaur*}

Department of Oral Medicine and Radiology, Genesis Institute of Dental Sciences and Research, Ferozepur, Punjab, India

\begin{abstract}
Papillon-Lefevre syndrome is a rare autosomal recessive genetic disorder. The clinical manifestations include palmer planter hyperkeratosis with precocious progressive periodontal disease that results in premature exfoliation of primary and permanent dentitions. Patients are often edentulous at an early age.
\end{abstract}

\section{Introduction}

Papillon lefevre is a rare genodermal condition characterized firstly by two French Physicians Papillon and Lefevre in 1924, in a brother and sister suffering from palmoplantar hyperkeratosis associated with early onset periodontitis and pre mature loss of deciduous as well as permanent dentition [1]. Gorlin et al. in 1964 [2] have added the third component of dural calcification for making diagnosis of this syndrome. It has a prevalence of 1-4 cases per million in general population and the carrier frequency appears to be $2-4$ per thousand population with no sexual predominance [3-6].

A genetic predisposition with greater frequency of occurrence in consanguineous offspring has been reported [7]. It may be attributed to high rate of consanguineous marriages in Arab communities [8,9].

The pathogenesis of Papillon Lefevre syndrome is still controversial. The skin lesions are thought to be because of disturbances in ectodermal and mesodermal components but there is no reason to explain the rapid loss of all the deciduous as well as permanent teeth in the order of their eruption [10].

Two new aspects for the pathogenesis of PLS have been discovered. First, some patients suffering from PLS exhibit cellular immune defect with decreased chemotactic and phagocytic function of neutrophils and other granulocytes [11]. Second, some pathogenic micro-organisms as porphyromonas gingivalis, capnocytophaga gingivalis, actinobacillus actinomycetemcomitans, peptostreptococcus micros, fusobacterium nucleatum, and spirochetes have been implicated as the causative agents for periodontal problems in PLS [12].

Manifestations of PLS usually appear between the age of 6 months to 4 years, coinciding with the eruption timing of deciduous dentition $[4,13]$. The palmoplantar keratosis typically manifest as well demarcated keratotic plaques over the surface of palms and soles [14]. Sometimes, these plaques may be associated with hyperhydidrosis of hands and feet, hence resulting in foul smelling odor [2]. Usually these plaques get worsen in winters and had associated fissured lesions [14].

In the field of dentistry, the most significant finding is early onset periodontitis which usually get started at the age of 3-4 years. The gingivae is inflamed, bleed on slight provocation leading to rapid destruction of underlying periodontium. This rapidly progressing periodontitis is usually unresponsive to traditional periodontal treatment modalities. The development and eruption of the deciduous teeth occur normally but shedding occurs prematurely mostly by the age of 3-4 years. After the shedding the gingivae appears to be normal and condition again worsens with the eruption of the permanent teeth. The patient usually shed off all his or her permanent teeth by the age of 13-16 years. Later on third molars undergo the same fate. Because of resorption of underlying alveolar bone, teeth appear as floating in air in radiographs [15-17].

The degree of dermatologic involvement may not be related to the level of periodontal infection [18]. Nail changes such as transverse grooving and fissuring are apparent in advanced cases [19].

The purpose of this paper is to demonstrate clinical as well as radiological features of Papillion Lefevre Syndrome.

\section{Case Report}

A 17 year old female patient presented to the department of Oral Medicine and Radiology, Genesis Institute of Dental Sciences and Research, Ferozepur, Punjab, India, with the chief complaint of multiple loss of teeth.

Clinical history revealed that she had normal emergence of deciduous teeth at 8-9 months of age, which started loosening at three years and were all eventually lost by four years of age. Patient was not sure about the time of eruption of permanent teeth, but described gingival bleeding during brushing and eating, after the eruption of permanent teeth. There was loosening of permanent teeth from 10 years of age and eventually many permanent teeth were lost by 17 years of age. Bleeding was also associated at the time of tooth loss. She visited a private dentist who replaced her upper anteriors, right maxillary posteriors and left mandibular posteriors with fixed partial denture 3 years before. Now her all teeth were grade III mobile. Detachment of gingivae can be seen in (Figure 1).

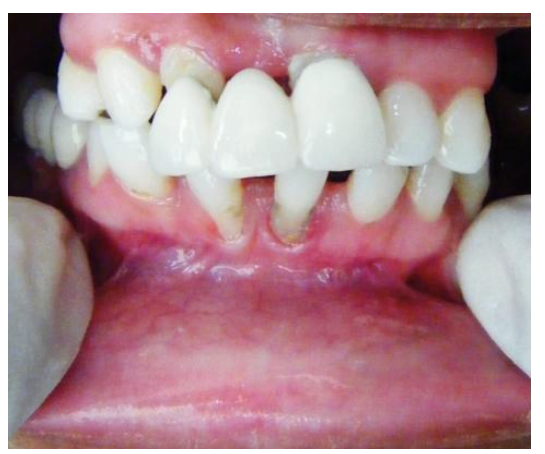

Figure 1: Poor Periodontal status of teeth.

*Corresponding author: Dr. Bhawandeep Kaur, Department of Oral Medicine and Radiology, Genesis Institute of Dental Sciences and Research, Ferozepur, Punjab, India, Tel: +91-8146375602, E-mail: drbhawana@yahoo.co.in

Received April 10, 2013; Accepted July 10, 2013; Published July 13, 2013

Citation: Kaur B (2013) Papillon Lefevre Syndrome: A Case Report with Review. Dentistry 3: 156. doi:10.4172/2161-1122.1000156

Copyright: (c) 2013 Kaur B. This is an open-access article distributed under the terms of the Creative Commons Attribution License, which permits unrestricted use, distribution, and reproduction in any medium, provided the original author and source are credited. 


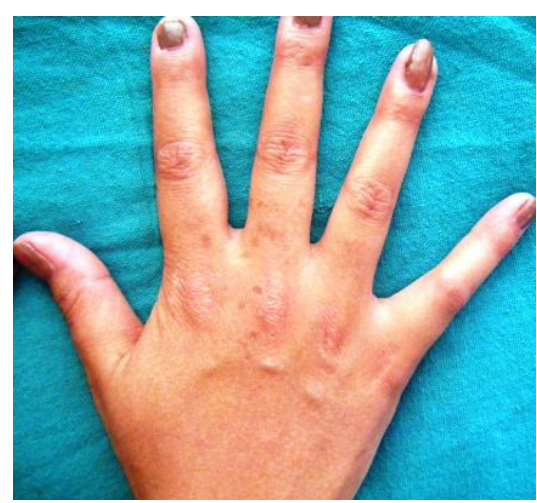

Figure 2: Keratotic Plaque on the dorsal surface of right hand.

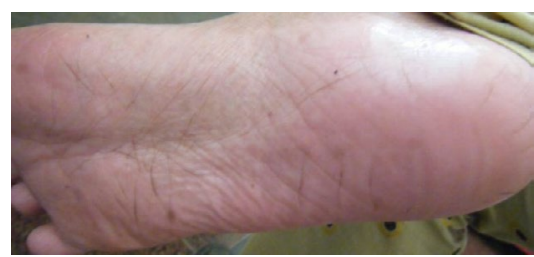

Figure 3: Keratotic plaques on the ventral surface of the left foot.

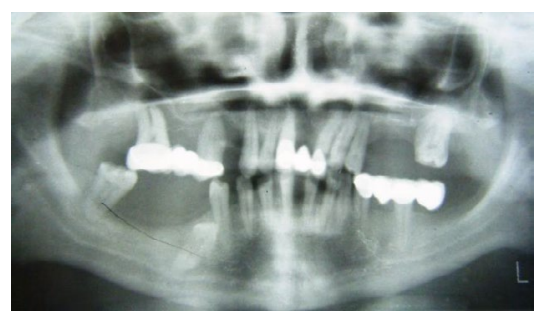

Figure 4: Panoramic radiograph showing severe alveolar bone loss.

Medical history was noncontributory. Parents were not of consanguineous marriage. In pregnancy history of mother, she had full term uneventful pregnancy.

The patient was moderately built with a steady gait. Her physical and mental development was also normal. Dermatological examination revealed dry skin with normal development of hair and nails. There were symmetric, well-demarcated, brownish, keratotic, plaques affecting the skin of her palms on the dorsal surface and soles on the ventral surface as seen in (Figure 2 and 3). Panaromic view showed generalized loss of alveolar bone, complete loss of bone support around all the present teeth as well as impacted 45 as seen in (Figure 4).

\section{Discussion}

PLS is an autosomal recessive inherited disorder, it means both parents will be phenotypically healthy and must carry the autosomal gene for the syndrome, no family history of the disorder except for the affected person and some siblings. PLS is suggested to be because of mutation in cathepsin $\mathrm{C}$ gene located on chromosome 11q14.1-q21 [20]. This cathepsin C gene encodes for cysteine lysosomal protease known as dipeptidyl-peptidase I. It removes dipeptides from amine terminals of the protein substrates. This gene is expressed in epithelial regions and in various immune cells like PMNLs, macrophages and their precursors. 16 In PLS, most severely affected regions are the keratinized gingivae of oral cavity, skin of palms and soles.
Lysosomal protease enzyme plays an important role in maintaining the balance between oral microflora and immune system through protein degradation and proenzyme activation. Mutation in this enzyme lead to altered host response to pathogenic microorganisms in dental plaque. It is documented in literature that alterations in cathepsin C gene lead to pre pubertal periodontitis in PLS patients [6,21,22].

Beside genetic predisposition, certain environmental factors like viral and bacterial infections of actinobacillus actinomycetemcomitans, capnocytophaga, cytomegalo and Epstein Barr virus etc also play an important role in pre pubertal periodontitis of PLS patients [23-25].

Along with the above, altered function of monocytes, lymphocytes, reversed ratio of $\mathrm{T}$ helper and $\mathrm{T}$ killer cells, disruption of fibroblast and cementoblast function with defective periodontal ligament attachment and gingival epithelium [11,26-30]. All this accumulated evidence indicate that etiopathogenesis of PLS is complex interaction between immune mediated deficiencies in the host defense mechanism and inherited genetic defects.

PLS has varied clinical presentations as documented by various authors. According to Willet et al. in 1985, patients with PLS may have late onset periodontitis and early onset palmoplantar hyperkeratosis [31].

Bullon et al. in 1993 documented a case report of 2 sisters exhibiting early onset palmoplantar hyperkeratosis and late onset periodontitis [32]. Brown et al. in 1993 described 3 cases having late onset periodontitis as well as skin manifestations [33].

Mutations in Cathepsin C gene result in PLS and an interesting feature is that these mutations can also result in two another closely related conditions namely Haim Munk Syndrome and pre pubertal periodontits. HMS is autosomal recessive genodermatological disorder characterized by palmoplantar hyperkeratosis and periodontitis. While other important clinical findings in HMS are recurrent pyogenic skin infections, acro-osteolysis, atrophic changes in nails, arachnodactyly and fingers having tapered phalangeal ends and these cutaneous findings have been reported to be more severe and extensive as compared to PLS [34].

Pre pubertal periodontitis is characterized by rapidly progressive early onset periodontitis with destruction of periodontium of both deciduous and permanent teeth. This destruction may be localized to one quadrant or may be generalized. The radiographic presentation of alveolar bone loss in pre pubertal periodontitis may resemble as that in case of PLS but palmoplantar hyperkeratosis will be present in PLS not in Pre pubertal periodontitis.

Features of PLS found in our patients were

1. Inflammed and swollen gingivae

2. Bleeding on probing on slight provocation

3. Mobitily of teeth

4. Deep infra bony pockets

5. Severe alveolar bone loss

6. H/O of early loss of multiple teeth in case

7. Lesions subside with exfoliation of teeth

8. Hyperkeratotis papules present on the hands and soles

9. Teeth Development, form and eruption were normal 
10. At times of tooth eruption, the gingiva becomes erythematous and swollen and after eruption it manifests bleeding on probing on slight provocation.

11. After exfoliation or removal of the tooth, the gingiva regains normal appearance.

\section{Negative family history}

Ullbro et al. in 2003 found no association between the degree of palmoplantar hyperkeratosis and severity of periodontitis, suggesting that these two major components of PLS are not related to one another [35].

PLS should also be differentiated from other conditions like acrodynia, hypophosphatasia, histiocytosis X, leukemia, cyclic neutropenia associated with periodontitis and pre mature loss of teeth. In all the above mentioned conditions palmoplantar hyperkeratosis is not a feature.

PLS should also be differentiated from conditions causing palmoplantar hyperkeratosis like Howel Evans Syndrome, Keratosis punctata, Vohwinkel's Syndrome, Greither's Syndrome. In these conditions, periodontitis is not a characteristic feature as in PLS.

PLS debilitates individuals socially, psychologically and physically. So a multidisciplinary approach should be adopted to treat such patients. Skin manifestations are usually treated with oral retinoids. Oral retinoids including acitretin, eterinate, isotretinoin are the mainstay of the treatment of both hyperkeratosis and periodontitis [14]. Treatment may be more beneficial if it is started during eruption and maintained during the development of permanent dentition. Usually the periodontitis is difficult to control once it manifests in PLS [19].

Different treatment modalities of PLS may include:

Intensive periodontal therapy

Maintenance of oral hygiene

Extraction of teeth having poor prognosis

Rehabilitation of patient's oral cavity

Alveolar bone augmentation

Dental implants

For skin lesions retinoids, local and systemic antibiotics can be prescribed by taking consent from the dermatologist.

Continuous monitoring and frequent recall appointments have shown to minimize the periodontal deterioration.

Treatment done in our cases was the extraction of severely mobile teeth followed by prosthetic rehabilitation. The patients were educated as well as counseled for implant supported prosthesis but due to socioeconomic reasons removable prosthesis was fabricated.

\section{Conclusion}

The dental professional is mostly first one to detect the periodontal manifestations of patients suffering from PLS. A thorough knowledge of all the symptoms and signs of this syndrome as well other conditions having similar manifestations may help the dentist to make a diagnosis of the syndrome at an early stage. Hence dentist can prevent the loss of permanent teeth by early institution of oral retinoinds during the eruption of permanent teeth. Even if the patient comes at later stages, dentist can administer prompt periodontal treatment regimens to preserve disease free teeth with early extraction of affected teeth to prevent the alveolar bone loss.

\section{References}

1. Papillon MM and Lefevre $P$ (1924) Deux cas de keratoderma palmaire et plantaire symmetrique familial (maladie de Meleda) chez le frère et la soeur: coexistence dans les deux cas d'alterations dentaire graves. Bull $\mathrm{Soc} \mathrm{Fr}$ Dermatol Syph 31: 82-87.

2. Gorlin RJ, Sedano H and Anderson VE (1964). The syndrome of palmoplantar hyperkeratosis and premature periodontal destruction of the teeth. J Pediatr 65: 895-908

3. French D, Scott $\mathrm{H}$ and Overall CM (1995) Papillon Lefevre syndrome associated early onset periodontitis: A review and case study. J Can Dent Assoc 61: 432438 .

4. Hattab FN, Rawashdeh MA Yassin OM, Al-Momani AS and Al-Ubosi MM (1995) Papillon Lefevre syndrome: A review of Literature and report of 4 cases. J Periodontol 66: 413-420.

5. Abdulwassie H, Dhanrajani PJ and Jiffry A(1996) Papillon Lefevre syndrome I-Reappraisal of etiology, clilnical features and treatment, II- Oral rehabilitation using osseointegrated implants. Indian J Dent Res 7: 63-70.

6. Cury VF, Costa JE, Gomez RS, Boson WL, Loures CG, et al. (2002) A nove mutation of the cathepsin $\mathrm{C}$ gene is Papillon- Lefevre syndrome. J Periodontol 73: 307-12.

7. Hattab FN and Amin WM (2005) Papillon Lefevre syndrome with albinism: A review of Literature and report of 2 brothers. Oral Surg Oral Med Oral Pathol Oral Radiol Endod 100: 709-16.

8. Khoury SA and Massad DD (1992) Consanguineous marriage in Jordon. Am Med Genet 43: 206-210.

9. Altalabani J, Shubbar Al and Mustafa KE (1998) Major congenital malformations in the United Arab Emirates (UAE): need for genetic counseling. Ann Hum Genet 62: 411-418.

10. Kothiwale SV and Mathur S (2008) Partial expression of Papillon Lefevre syndrome. Indian J Dent Res 19: 264-266.

11. Schroeder HE, Seger RA, Keller HU and Rateitschak-Pluss EM (1983) Behaviour of neutrophilic granulocytes in a case of Papillon Lefevre syndrome. J Clin Periodontol 10: 618-635.

12. Newman M, Angel I, Karge H, Weiner M, Grinenko V, et al. (1977) Bacterial studies of Papillon Lefevre syndrome. J Dent Res 56: 545.

13. Hart T and Shapira (1994) Papillon Lefevre syndrome. Periodontol 2000. 6 88-100.

14. Siragusa M, Romano C, Batticane N, Batolo D and Schepis C (2000) A new family with Papillon Lefevre syndrome: effectiveness of etretinate treatment Cutis 65: 151-155.

15. Mahajan VK, Thakur NS and Sharma NL (2003) Papillon Lefevre syndrome. Indian Pediatr 40: 1197-1200.

16. Janjua SA and Khachemoune (2004) Papillon Lefevre syndrome: Case report and review of literature. Dematol Online J 10: 13

17. Galanter DR and Bradford S (1969) Case report, Hyperkeratosis palmoplantaris and periodontosis: The Papillon Lefevre syndrome. J Periodontol 1: 40-47.

18. Ullbro C, Crosner CG, Nederfors T and Thelstrup-pederson K (2003) Dermatologic and Oral findings in a cohort of 47 patients with Papillon Lefevre syndrome. J Am Acad Dermatol 48: 345-351.

19. Subramaniam P, Mathew $S$ and Gupta KK (2008) Papillon Lefevre syndrome: A case report. J Indian Soc Pedod Prevent Dent 26: 171-174.

20. Laass MW, Hennis HC, Preis S, Steven HP, Jung M, et al. (1997) Localization of a gene for Papillon Lefevre syndrome to chromosome 11q14-q21 by homozygosity mapping. Hum Genet 101:376-382.

21. Toomes C, James J, Wood AJ, Wu CL, McCormick D, et al. (1999) Loss of function mutations in the cathepsin $\mathrm{C}$ gene result in periodontal disease and palmoplantar keratosis. Nat Genet;23: 421-424.

22. Gorlin RJ (2000) Of palms, soles, and gums. J Med Genet 37: 81-82.

23. Tinanoff N, Tanzer JM, kornman KS and Maderazo EG (1986) Treatment of the periodontal component of Papillon Lefevre syndrome. J Clin Periodonto 13: 6-10. 
24. Preus HR (1988) Treatment of rapidly destructive periodontitis in Papillon Lefevre syndrome: laboratory and clinical observations. J Clin Periodontol 15: $639-643$

25. Velazco CH, Coelho C, Salazar F, Contreras A, Slot J, et al. (1993) Microbiologic features of Papillon Lefevre syndrome periodontitis. J Clin Periodontol 20: 622 627.

26. Preus HR and Morland B (1987) In vitro studies of monocytes function in two siblings of Papillon Lefevre syndrome. Scand J Dent Res 95: 59-64.

27. Levo Y, Wollner S and Hacham -Zadeh S (1980) Immunological study of patients with Papillon Lefevre syndrome. Clin Exp Immunol 40: 407-410.

28. Vrahopoulous TP, Barber P, Likoni H and Newman HN (1988). Ultra structure of periodontal lesion in case of Papillon Lefevre syndrome. J Clin Periodontol 15: 17-26.

29. Lu HKJ, Lin CT and Kwan HW (1987) Treatment of patient with Papillon Lefevre syndrome: a case report. J Periodontol 58: 789-793.

30. Celenligil H, Kansu E, Ruacan S and Eratalay K (1992) Papillon-Lefevre syndrome: characterization of peripheral blood and gingival lymphocytes with monoclonal antibodies. J Clin Periodontol 19: 392-397.

31. Willett L, Gabriel S, Kozma C and Bottomley W (1985) Papillon Lefevre: report of a case. J Oral Med 40: 43-45.

32. Bullon P, Pascual A, Fernandez-Novoa MC, Borobio MV, Muniain MA, et al. (1993) Late onset of Papillon Lefevre syndrome: a chromosomic, neutrophic function and microbiologic study. J Clin Periodontol 20: 662-667.

33. Brown RS, Hays GI, Flaitz CM, O’Neill PA, Abramovitch K, et al. (1993) A possible late onset variation of Papillon Lefevre syndrome: report of 3 cases. $J$ Periodontal 64: 379-386.

34. Hart TC, Hart PS, Michalec MD, Zhang Y, Firatli E, et al. (2001) Haim Munk syndrome and Papillon Lefevre syndromes are allelic mutation in cathepsin $\mathrm{C}$ . J Med Genet 38: 79.

35. Ullbro C, Crossner C-J, Lundgren T, Stalblad P-A and Renvert S (2000) Osseointegrated implants in a patient with Papillon Lefevre syndrome: a 4 1/2year follow up. J Clin Periodontol 27: 951-954. 